\title{
Tributilo estanho: Um inimigo ambiental
}

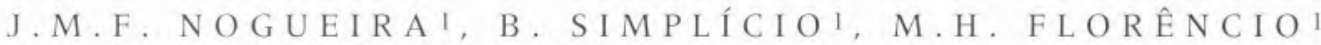 \\ e A.M.M. BETTEN COURT2
}

\section{INTRODUÇÃO}

A temática ambiental só surgiu há umas escassas dezenas de anos, inicialmente em alguns espíritos científicos mais preocupados, sendo depois extensiva de forma natural e acelerada aos demais cidadãos. Na realidade, assistimos a uma rápida consciencialização relativamente aos problemas ambientais, sendo que em muitos casos foram comprovadas as preocupações que outrora não passavam de meras utopias.

Partindo do pressuposto de que o ambiente é a base do desenvolvimento e que, sem ambiente adequado não há desenvolvimento que perdure, todas as acções do Homem deverão objectivar uma valorização e utilização racional dos recursos naturais.

A água é um desses preciosos recursos e os recentes problemas de poluição gerados, levaram a uma crescente necessidade de se procurar uma compatibilização harmoniosa entre o Homem e o bem precioso, mas escasso, que é a água.

Já no séc. XVI, as preocupações com a qualidade da água eram evidentes, de tal modo que se podia encontrar nas Ordenações do Reino o seguinte registo:

"Pessoa alguma não lance nos rios e lagoas, trovisco, barbasco, cola, cal nem outro material, com que o peixe se mate; e quem o fizer, sendo Fidalgo ou Escudeiro, he degredado para África; e sendo de menor qualidade he açoutado (Liv.5. Tit.8887)."

Com o acentuado crescimento populacional e em particular dos grandes pólos urbanos, passaram a ser produzidas grandes quantidades de efluentes domésticos e industriais e consequentemente a qualidade dos recursos hídricos ultrapassou em muitos casos a capacidade do meio, para rapidamente proceder à degradação das substâncias aí lançadas.

Os estuários são particularmente afectados pelo uso indiscriminado deste recurso, dada a enorme pressão a que se encontram sujeitos, uma vez que são quase sempre escolhidos como zonas portuárias para implementação de grandes centros industriais, localização de centros urbanos importantes, recebendo ainda, em simultâneo, o escoamento de toda a bacia hidrográfica do rio onde podem existir as mais diversas actividades marítimas.

A análise de espécies químicas que de uma forma ou de outra possam interferir negativamente com o meio ambiente, tornou-se deste modo cada vez mais importante para uma melhor compreensão das repercussões ao nível dos diferentes ecossistemas e a respectiva interacção nos diferentes ciclos biogeoquímicos.

Neste contexto, os derivados orgânicos de estanho são considerados entre os compostos mais tóxicos alguma vez introduzidos deliberadamente nos ecossistemas naturais pelo Homem.

\section{O USO INDISCRIMINADO DE TRIBUTILO ESTANHO}

Após o reconhecimento, nos anos cinquenta, das propriedades biocidas dos trialquilorgano-estanhos, o uso e aplicação destes compostos sofreu um aumento considerável a partir desta data. De um valor de cerca de 5000 ton/ano no início dos anos sessenta, passou-se para um valor superior às 60000 ton nos finais dos anos oitenta, sendo actualmente os compostos organometálicos mais usados.

Desta gama de compostos, destacam-se os tributilo-estanhos (TBT) que são usados sobretudo na composição das tintas antivegetativas, que impedem o desenvolvimento de incrustações em barcos, navios e docas. Actuam, ainda, como agentes fungicidas, bactericidas, insecticidas, acaricidas e miticidas na agricultura e como agentes preservadores da madeira, têxteis, couro, equipamento eléctrico entre outros tipos de materiais.

Enquanto que os triorgano-estanhos constituem os principais agentes biocidas, os mono e diorgano-estanhos são utilizados na produção de cloreto de polivinilo como estabilizadores da radiação ultravioleta e da temperatura e como catalisadores na produção das espumas de poliuretano. Embora constituam cerca de $70 \%$ do consumo total de organo-estanhos, estes compostos não constituem um perigo directo para o ambiente. É sim, a sua aplicação como agentes biocidas que constitui uma forma directa de emissão destes compostos para os ecossistemas naturais.

A actividade antibiológica do TBT contra fungos, bactérias e algas foi pela primeira vez reconhecida na década de cinquenta por Van der Kerk e Luijten no Instituto de Química Orgânica da Holanda. O óxido de bis-tributilo-estanho foi um dos primeiros compostos a ser aplicado nas tintas antivegetativas, entre os anos de 1959 e 1961, actuando como agente anti-incrustante dos cascos dos navios, barcos de recreio e docas.

As tintas antivegetativas utilizadas actualmente, baseiam-se, salvo raras excepçōes, em veículos fixos de secagem física. Os componentes bioactivos que entram na respectiva composição dissolvem-se lentamente na água do mar, formando uma película em redor do casco, rica em elementos tóxicos que interferem com o processo biológico dos organismos marinhos impedindo a sua fixação. À 
medida que a embarcação navega, a acção biocida desenvolve-se a uma velocidade maior por efeito da turbulência da água e da fricção da mesma sobre o casco. A possibilidade de regular e controlar esta libertação de biocidas, reside na diferença principal entre os diversos tipos de tintas antivegetativas, nomeadamente, antivegetativos convencionais de matriz solúvel, de matriz insolúvel e autopolimentantes.

No início da década de oitenta houve um aumento considerável das preocupações ambientais quanto ao uso dos derivados orgânicos de estanho, especialmente no meio aquático. Este reconhecimento foi sobretudo acentuado com o alerta dos efeitos tóxicos provocados pelos compostos de TBT ao nível do crescimento e reprodução da espécie Crassostrea gigas, também designada por "ostra do Pacífico".

Com o passar dos anos, novos registos foram também ao encontro das preocupações ambientais, revelando que a presença destes compostos conduzia a um decréscimo acentuado em diferentes estádios do desenvolvimento de alguns organismos marinhos ou mesmo ao nível da cadeia alimentar onde os mesmos se inseriam, nomeadamente do "nanoplancton".

Uma estimativa relativa ao ano de 1985 , indicava que 20 a $30 \%$ dos navios que circulavam em todo o mundo utilizavam este tipo de tintas, ao mesmo tempo que os custos relativos à produção de antivegetativos para o ano de 1975 eram superiores a 1 bilião de USD/ano. Com o decorrer dos anos as preocupações foramse acentuando com a descoberta de novos efeitos catastróficos ao nível do meio aquático, nomeadamente a quase extinção das populações da espécie Nucella lapillus no sudoeste de Inglaterra. Assim, o reconhecimento gradual das implicações nefastas ao nível ambiental por parte destes compostos, levou à introdução de normas regulamentares para controlo do respectivo uso.

A França foi o primeiro país europeu, em 1982, a banir as tintas antivegetativas em barcos com comprimento inferior a $25 \mathrm{~m}$, seguida do Reino Unido em 1986, que começou por restringir a venda a retatho de agentes antivegetativos em tintas copoliméricas contendo um teor inferior a $7,5 \%$ em estanho total ou $2,5 \%$ em estanho livre. Ficou igualmente estabelecido pelo governo britânico, uma meta de qualidade ambiental a atingir para o TBT, $20 \mathrm{ng} \mathrm{dm}^{-3}$, por forma a salvaguardar os estuários e as águas costeiras. Um ano após estas medidas, em 1987, foi declarado por responsáveis do Departamento de Ambiente Britânico que tais medidas se revelavam ainda insuficientes, tendo sido proibida desde então a utilização de TBT em tintas antivegetativas para barcos com comprimento inferior a $25 \mathrm{~m}$ e declarado uma nova meta de qualidade ambiental, $2 \mathrm{ng} \mathrm{dm}^{-3}$

Em 1980, a Marinha dos Estados Unidos começou igualmente a aperceber-se dos potenciais riscos inerentes a este tipo de compostos, proibindo a utilização das tintas antivegetativas também em embarcações inferiores a $25 \mathrm{~m}$ e sem alumínio na sua constituição, uma vez que a aplicação de outro agente antivegetativo iria resultar numa corrosão precoce. Diversos estados norte-americanos adoptaram em 1988, um valor limite para o TBT de $2 \mathrm{ng} \mathrm{dm}^{-3}$ e por outro lado, foi requerida uma taxa de libertação inferior a $4,0 \mathrm{mg} \mathrm{cm}^{-2} / \mathrm{dia}$, para navios de grande porte.

Nos países da União Europeia, o uso de TBT em tintas antivegetativas foi completamente banido durante a década de noventa e actualmente, a meta considerada de qualidade am-
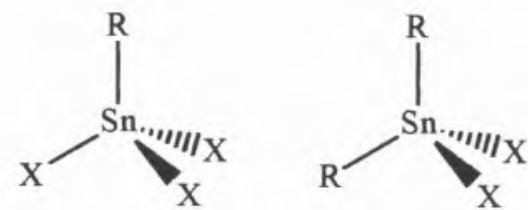

biental que minimiza os efeitos tóxi$\cos$ nas diversas populações biotas. cifra-se em concentrações de TBT inferiores a $1 \mathrm{ng} \mathrm{dm}^{-3}$, apesar de persistirem no ambiente concentrações superiores.

Em Portugal, o decreto-lei n. ${ }^{\circ} 54 / 93$ de 26 de Fevereiro, que estabelece diversas medidas relativas à limitação do uso, fabricação e comercialização de certas substâncias perigosas, como são o caso dos organo-estânicos, foi introduzido com o objectivo de salvaguardar a saúde pública e o meio ambiente em geral.

Todavia e não obstante uma clara preocupação, por parte de diversos países, em limitar ao máximo o uso deste tipo de compostos, a verdade é que as tintas antivegetativas à base de TBT são, ainda, de extrema importância na aplicação em navios de grande porte, resultando numa presença significativa do mesmo em alto mar. Esta constatação, é suportada por vários registos que evidenciam a presença de compostos orgâni$\cos$ de estanho nas principais rotas marítimas quer nacionais quer internacionais, com todas as implicações nefastas que isso representa para uma grande variedade de espécies marinhas.

\section{A QUÍMICA DOS COMPOSTOS DE ESTANHO}

Os compostos orgânicos de estanho consistem genericamente num átomo central de estanho no estado tetravalente, ligado covalentemente a um ou mais grupos alquilo, como é reproduzido na Fig. 1.

Fig. 1 - Fórmulas genéricas para os compostos orgânicos de estanho. R-radical orgânico; X-radical inorgânico (habitualmente halogeneto ou hidróxido) ou radical orgânico polar (acetato). 
A informação completa sobre o destino dos compostos organoestânicos no meio aquático, é de extrema importância para o conhecimento e compreensão dos correspondentes efeitos ecotoxicológicos. Vários estudos efectuados ao longo dos anos, evidenciaram que a perigosidade destes compostos se encontra relacionada com a distribuição do TBT presente entre a fase dissolvida e a adsorvida em partículas em suspensão no meio aquático.
Em condições normais, o TBT pode ocorrer sob diferentes formas, encontrando-se todas em equilíbrio umas com as outras. Assim, para um valor de $\mathrm{pH}$ do meio inferior a 6,5 a espécie predominante é o catião $\mathrm{TBT}^{+}$e para um valor superior predomina a forma de complexo neutro. A pH 8, sendo o valor máximo para a água do mar igual a 8,3 . podem ocorrer diversas formas como o cloreto, hidróxido e carbonato de TBT, entre outras, se bem que a maior toxicidade para os organismos

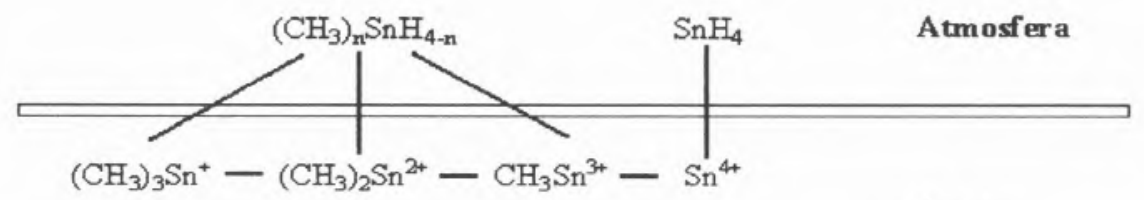

Águ a

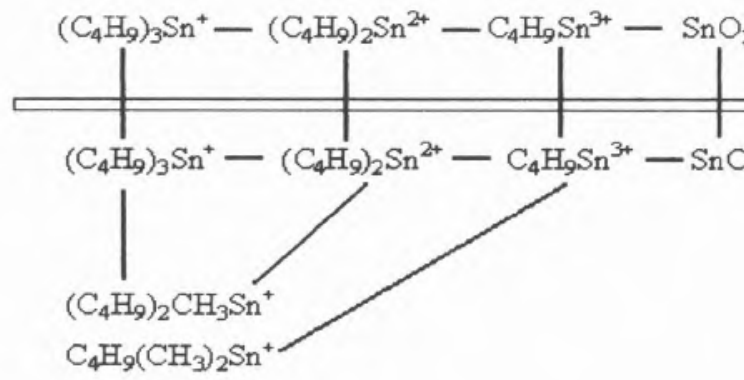

Fig. 2 - Ciclo biogeoquímico para os compostos de estanho.

Enquanto que os butilo-estanhos são exclusivamente de origem antropogénica, os metilo-estanhos podem resultar ou não de metilações biológicas que ocorrem ao nível ambiental.

Uma vez na água, o TBT é submetido simultaneamente a processos de clivagem por degradação química, fotoquímica e bioquímica, resultando como principais produtos de degradação o monobutilo-estanho (MBT), o dibutilo-estanho (DBT) e o estanho inorgânico (Sn (IV)). O TBT sofre, ainda, processos de eliminação da coluna de água por adsorção à matéria em suspensão, por sedimentação e por ligação a alguns microorganismos. A Figura 2 evidencia o ciclo biogeoquímico para os compostos de estanho. marinhos advém da forma neutra. A Figura 3 apresenta as principais formas de TBT que podem estar presentes na água do mar.

$\begin{array}{ll}\text { TBTX } & \Leftrightarrow \mathrm{TBT}^{+}+\mathrm{X}^{-} \\ \mathrm{TBTOH}^{+} & \Leftrightarrow \mathrm{TBT}^{+}+\mathrm{OH}^{-} \\ \text {TBTCO }_{3} & \Leftrightarrow \mathrm{TBT}^{+}+\mathrm{CO}_{3}^{2-}\end{array}$

\section{Fig. 3 - Principais formas de TBT presentes} na água do mar (X: $\mathrm{Cl}_{-}, \mathrm{F}$ - ou $\left.\mathrm{O}^{2-}\right)$.

A capacidade de adsorção evidenciada por contaminantes orgânicos neutros, como são o caso dos compostos organo-estânicos, depende fortemente da natureza da matéria orgânica presente na água, do tipo de partículas suspensas bem como dos sedimentos. Estes compostos tendem a ficar retidos sobretudo em materiais inorgânicos, como por exemplo minérios argilosos, óxidos de ferro hidratados e ácidos húmicos e fúlvicos. Esta capacidade de adsorção é considerada um dos mais importantes processos responsáveis pela redução da concentração e assim, pela toxidade destes compostos no meio aquoso.

De acordo com Ritsema, os valores dos coeficientes de partição, $\mathrm{K}_{\mathrm{p}}=\mathrm{C}_{\mathrm{s}} / \mathrm{C}_{\mathrm{w}}{ }^{*}\left(\mathrm{dm}^{-3} \mathrm{~kg}^{-1}\right)$, para o TBT variam entre 200 e 200000 segundo diversas condições, nomeadamente de $\mathrm{pH}$, salinidade, concentração das partículas e quantidade de material orgânico.

Contudo, prolongadas exposições a altos teores de TBT na água, provenientes da desagregação destes compostos das tintas antivegetativas, resultam em concentrações elevadas quer na fase aquosa, quer nos sedimentos, podendo originar coeficientes de partição considerados normais.

Quando os níveis de TBT diminuem significativamente, por exemplo, em virtude da proibição de tintas antivegetativas, verifica-se que este processo ocorre mais rapidamente na água do que nos sedimentos, devido aos mecanismos de fotodegradação que só se dão ao nível da fase aquosa. Neste caso, são observados baixos teores de TBT na água e uma concentração acentuada nos sedimentos, traduzindo-se em coeficientes de partição particularmente elevados nesses locais. Em ambos os processos de degradação química e microbiológica ocorre a di-alquilação da molécula de TBT. Nas águas com baixos índices em matéria suspensa, prevalece a fotodegradação enquanto que para valores elevados predominam os mecanismos de biodegradação. Durante o verão, ambos os processos desempenham um papel fundamental na fase aquosa, conduzindo a tempos de meia vida compreendidos entre os 6 e os 19 dias, enquanto que no inverno, os valores situam-se entre os 12 e os 200 dias. 
Embora os mecanismos de degradação sejam predominantemente de origem biótica, a ligação $\mathrm{Sn}-\mathrm{C}$ pode ser quebrada por quatro diferentes processos abióticos: radiação ultravioleta, clivagem química, radiação gama e clivagem térmica. Os dois últimos processos ocorrem com uma contribuição diminuta na degradação do TBT no meio ambiente, pois a ligação Sn-C é estável acima dos $200{ }^{\circ} \mathrm{C}$ e raramente está exposta a radiações gama. Energeticamente, somente na região $(300-350 \mathrm{~nm})$ dos raios ultravioleta é suposto dar-se a fotólise directa do TBT, facto que só ocorre ao nível dos primeiros centímetros da camada superficial da coluna de água devido à reduzida transmitância da luz. Assim, o TBT retido ao nível dos sedimentos, constitui uma substancial ameaça para a vida aquática podendo ser apenas reposto em circulação por ressuspensão natural, tempestades, pelas operações de dragagem e por reciclagem das partículas para a água, por parte de organismos específicos.

O tempo de meia vida para o TBT na água é relativamente pequeno, de dias ou semanas dependendo das condições locais, quando comparado com o dos sedimentos que pode ir desde dias até vários anos, consoante se trate respectivamente de zonas aeróbicas ou anaeróbicas. Desta forma, os sedimentos funcionam como um repositório com o consequente aumento da persistência deste tipo de compostos nos ecossistemas aquáticos.

Para as baixas concentrações em que o TBT costuma ser detectado no meio ambiente, geralmente situadas na ordem das partes por bilião ou trilião (ppb's ou ppt's), diversas metodologias analíticas são genericamente implementadas. Os esquemas analíticos mais comuns para dosear o TBT combinam três passos básicos, nomeadamente, pré-concentração do analito, que envolve a extracção do TBT de matrizes líquidas ou sólidas; separação cromatográfica, usando colunas capilares de alta resolução com diversas fases estacionárias, após prévia derivatização, em geral por alquilação com reagentes de Grignard, geração de hidretos ou formação de sais de cloreto; e finalmente, detecção por ionização de chama, fotometria de chama, captura electrónica e emissão atómica, assim como por emissão atómica de plasma induzida por microondas, espectrometria de absorção atómica de forno de quartzo, espectrometria de massa e espectrometria de massa acoplada a plasma induzido, como detecção "hifenada".

\section{A TOXICIDADE \\ DOS COMPOSTOS ORGANO-ESTÂNICOS}

Sendo os derivados orgânicos de estanho considerados sem dúvida os compostos organometálicos mais tóxicos presentes no meio natural, a acção nefasta deste tipo de substâncias pode diferir em muito da dos respectivos elementos inorgânicos, uma vez que apresentam geralmente um nível de toxicidade superior.

Os efeitos tóxicos de um elemento são estreitamente dependentes das propriedades físico-químicas com que este se apresenta, podendo as diferenças de solubilidade na água ou nos lípidos, estados de agregação, estruturas químicas e volatilidades contribuírem de forma decisiva para incrementar ou não, quer a toxicidade, quer a toxicodinâmica. Estas formas determinam também a respectiva dinâmica no ambiente, podendo em certos casos controlar os processos de troca nos ciclos biogeoquímicos globais.

O estanho no estado elementar e os correspondentes compostos inorgânicos, exibem uma reduzida toxicidade para os organismos vivos, uma vez que a baixa solubilidade que apresentam nos tecidos lipídicos dificulta o processo de bioacumulação. Contudo, quando ligados a um ou mais grupos orgânicos as respectivas propriedades físicoquímicas são amplamente modificadas, resultando num incremento das actividades biológicas, mobilidade e persistência.
Em geral, uma progressiva introdução de radicais orgânicos na série $\mathrm{R}_{\mathrm{n}} \mathrm{SnX} \mathrm{X}_{(4-n)}$, traduz-se num aumento da toxicidade da molécula, atingindose os valores mais elevados nos compostos trisubstituídos. No caso de R ser um grupo alquilo, existe uma diferença distinta na toxicidade da molécula consoante a dimensão da cadeia, a qual, acima de quatro átomos de carbono resulta numa diminuição nítida dos níveis de toxicidade, tornando compostos como os trioctiloestanhos, praticamente não tóxicos para os organismos vivos. O mesmo já não sucede para os TBT's, os trietilo-estanhos, os trifenilo-estanhos e os triciclohexilo-estanhos, que evidenciam desde logo sérias implicações toxicológicas para a globalidade dos organismos marinhos.

O perigo dos compostos organoestânicos para o Homem, começou por se tornar numa preocupação real quando em 1954 ocorreu o acidente de "Stalinon" em França. O "Stalinon" era um medicamento oral usado no tratamento de infecções ao nível da pele que causou mais de 2000 casos de intoxicação e 98 mortes, provavelmente motivado pelas impurezas associadas, à base de iodeto de trietilo-estanho. Por outro lado, a exposição humana verificada em diferentes industrias produtoras e manipuladoras deste tipo de compostos, levou igualmente à detecção de novos focos de intoxicação.

A relativa facilidade na transposição das membranas biológicas pelos triorgano-estanhos, conduz a efeitos tóxicos principalmente ao nível da actividade mitocôndrial, afectando seriamente o processo respiratório. As membranas das mitocôndrias são danificadas pelo avolumar a que ficam expostas, resultando num aumento da permeabilidade, razão pela qual os triorgano-estanhos actuam como surfactantes, no transporte de aniões $\mathrm{Cl}^{-}$e $\mathrm{OH}^{-}$através das mesmas, inibindo a fosforilação oxidativa do ADP a ATP. De igual modo, promovem a inibição das proteínas intracelulares devido à fácil coordenação entre as moléculas dos triorgano-estanhos com os aminoácidos, cistina e histidina. 
A toxicidade dos compostos organo-estânicos produz principalmente efeitos característicos ao nível de diversos seres marinhos, visto o ambiente aquático ser o mais afectado. Para além de vários registos que comprovam a bioacumulação destes compostos ao nível dos diferentes orgãos e tecidos da fauna marinha, foram ainda diagnosticados processos de malformação e diminuição acentuada das taxas de crescimento e reprodução das respectivas populações. A Tabela 1 evidencia os efeitos negativos que o aumento em acetato de TBT promove na embriogénese e desenvolvimento larvar da espécie Crassostrea gigas.

As ostras são dos organismos marinhos mais estudados, em virtude de serem seriamente afectadas pela presença do TBT e correspondentes produtos de degradação. A literatura evidencia que em diferentes pontos do globo, diversas espécies de ostras sofreram uma diminuição acentuada da respectiva população, sucedendo que em muitos casos ocorreu a total extinção, face aos elevados níveis de exposição a este tipo de compostos, de que o anormal desenvolvimento da calcificação das conchas é das principais evidências. A título de exemplo, refira-se o sucedido no estuário do rio Tejo e ao longo da costa mediterrânica espanhola, com a quase extinção das populações da espécie Crassostrea angulata Lmk.

Um efeito cada vez mais estudado em alguns animais marinhos é a ocorrência de um fenómeno de pseudohermafrodismo, crescimento da genitália masculina em seres femininos, designado por "imposex", que se traduz na esterilização das fêmeas com o progressivo declínio das respectivas populações. Esta malformação, tem sido diagnosticada nos mais diversos organismos marinhos, com especial incidência nos neogastrópodes quer como predadores quer como presas, nos quais concentrações em TBT de apenas alguns ppt's poderem conduzir ao desaparecimento não só da própria espécie, como também de todas as restantes pertencentes à respectiva cadeia alimentar.

Tabela 1 - Exemplo dos efeitos da concentração em acetato de TBT na embriogénese e no desenvolvimento larvar da espécie Crassostrea gigas.

\begin{tabular}{|c|c|}
\hline $\begin{array}{l}\text { Acetato de TBT } \\
\qquad(\mu \mathrm{g} \mathrm{dm}-3)\end{array}$ & Efeitos na reprodução da Crassostrea gigas \\
\hline 100 & Inibição da fecundidade \\
\hline 50 & Inibição da segmentação \\
\hline 25 & Redução parcial da segmentação \\
\hline 10 & Ausência de formação de trocóforas* \\
\hline $3-5$ & Ausência de velígeras* e mal formação das trocóforas \\
\hline 0,5 & Numerosas anomalias, mortalidade ao fim de 10 dias \\
\hline 0,2 & Perturbações na assimilação do alimento, mortalidade total ao fim de 12 dias \\
\hline 0,1 & Crescimento retardado, mortalidade quase total após 12 dias \\
\hline 0,05 & Crescimento retardado, elevada taxa de mortalidade após 10 dias \\
\hline 0,02 & Não se observam efeitos \\
\hline
\end{tabular}

* Fases que ocorrem durante os diferentes estádios do desenvolvimento larvar

Refira-se que os organo-estânicos são os percursores de um grupo de compostos recentemente designado por xeno-estrogénios ou desreguladores endócrinos, que está provado afectarem o sistema hormonal sexual de diversas espécies de animais. As principais evidências apontam no sentido da redução da produção de esperma e aumento do cancro testicular para os machos, assim como da disfunção dos ovários, baixa fertilidade e aumento do cancro da mama para as fêmeas.

Os estuários dos rios nacionais, são igualmente alvo deste tipo de problemas e os mais recentes trabalhos de investigação comprovam o efeito negativo dos organo-estânicos sobretudo nas fêmeas das populações da espécie Hinla reticulata, nos estuários dos rios Tejo, Sado e Mira e em diversos pontos da costa sudoeste portuguesa.

\section{O CASO DO ESTUÁRIO DO RIO TEJO}

$\mathrm{O}$ rio Tejo possui certamente um dos estuários mais importantes da costa Atlântica europeia. Sucessivos estudos e programas, tornaram possível a respectiva caracterização hidrodinâmica, geoquímica, sedimentológica e ecológica. Envolve uma área com cerca de $300 \mathrm{~km}^{2}$, um volume de 1,8 $\mathrm{km}^{3}$ e uma profundidade hidráulica média de $10,6 \mathrm{~m}$. A descarga do rio varia sazonalmente, com valores médios típicos de cerca de $300 \mathrm{~m}^{3} \mathrm{~s}^{-1}$ para os meses de Maio a Novembro e na ordem dos $1000 \mathrm{~m}^{3} \mathrm{~s}^{-1}$ para os meses de Dezembro a Abril. Estudos relativos à distribuição vertical e horizontal da salinidade ao longo do estuário revelam uma diferença de 2 a $10 \%$ respectivamente, entre a água à superfície e a profunda. O tempo de residência de água doce no rio, calculado com recurso a modelos numéri$\cos$, situa-se entre os 10 e os 60 dias e o gradiente de salinidade ao longo do eixo atinge valores mais acentuados na secção a norte, onde o canal do rio se estende sob a forma de uma baía. A maior parte da área desta baía, apresenta valores compreendidos entre 26 e $33 \%$ de salinidade à superfície, pelo que o restante volume de água do estuário evidencia valores superiores.

São os caudais de renovação ou escoamento que podem ser várias vezes superiores ao caudal do próprio rio, sendo proporcionados pelo balanço de salinidade no estuário, conferindo-lhe um poder autodepurador. Os materiais poluentes dissolvidos, em suspensão ou flutuantes nas águas, tendem assim a ser expulsos do estuário ao fim de um ou mais ciclos de marés.

A complexidade do estuário, quer no respeitante às mais diversas utilizações quer no tocante às várias fontes que o poluem, traduziu-se por exem- 
plo no desaparecimento da ostreicultura como actividade produtiva, comprometendo o papel fundamental e insubstituível que a mesma desempenha do ponto de vista ecológico.

O estuário é ladeado pela cidade de Lisboa a norte e pelas cidades do Barreiro e Almada a sul, situando-se nesta margem a Reserva Natural do Estuário do rio Tejo, que para além de abranger parte considerável da superfície aquática, constitui um suporte essencial para a sobrevivência de uma grande biodiversidade de habitates sapais, lodos, águas pouco profundas, salinas, pastagens e arrozais.

Até 1973, os leitos de ostras que se podiam encontrar no estuário do rio Tejo eram considerados dos mais extensos da Europa. A espécie Crassostrea anqulata Lmk, também designada por "ostra portuguesa", representava uma fonte económica estimada em 13 milhões de USD/ano a preços correntes. A produção em larga escala centrava-se não só no estuário do rio Tejo como também no do rio Sado, tendo-se chegado a exportar 7500 ton /ano, durante os anos compreendidos entre 1962 e 1971.

Estas populaçōes foram desde muito cedo alvo de sucessivos estudos, face à morte prematura registada durante o período compreendido entre 1971 e 1972, tendo sido observada uma doença epidémica ao nível das "brânquias", para o qual contribuiu a abertura e a forte expansão aos navios de grande porte em ambos os estuários.

Com a demonstração de que os derivados orgânicos de estanho e em particular o TBT, apresentavam efeitos tóxicos de grande complexidade para diversas populações estuarinas, levando por exemplo a deficiências no desenvolvimento sexual de mais de 45 espécies de gastrópodes, rapidamente se multiplicaram os esforços para dimensionar estas mesmas implicações nas populações marinhas do estuário do rio Tejo.

$\mathrm{O}$ primeiro trabalho de Andreae e colaboradores em 1983, permitiu detectar a presença de MBT em amostras de água do estuário do Tejo, um dos principais produtos de degradação do TBT. Os teores encontrados eram particularmente elevados num dos pontos mais susceptíveis do estuário. local onde se situavam as unidades de construção e reparação naval da "Lisnave". Os resultados alcançados, não evidenciaram uma correlação conclusiva quanto ao desaparecimento gradual da espécie Crassostrea angulata $L m k$, se bem que o decréscimo sucessivo das rotas de navios no estuário do rio Tejo, não tenha coincidido com um aumento desta população, ao contrário do constatado em outros locais na Europa.

Os trabalhos consecutivos de Andreae e colaboradores no estuário do rio Tejo, evidenciaram concentrações médias na fase aquosa para o ião precursor BuSn ${ }^{3+}$ compreendidas entre 0,27 e $1,18 \mathrm{ng} \mathrm{dm}^{-3}$, valores esses superados em 1993 por Bettencourt e colaboradores, que detectaram concentrações médias situadas entre 0,76 e $5,26 \mathrm{ng} \mathrm{dm}^{-3}$.

Os estudos efectuados por Bet-tencourt e colaboradores, permitiram retirar diversas conclusōes, fundamentalmente que era possível a detecção das três espécies butilo, MBT, DBT e TBT, em quantidades mensuráveis nas amostras aquosas ao longo de todo o estuário. sendo a presença da última mais relevante, $1,13-21,13 \mathrm{ng} \mathrm{dm}^{-3}$. No que diz respeito à presença destas espécies em amostras de sedimentos do estuário do rio Tejo, o mesmo foi constatado, permitindo antever que as estações de amostragem na proximidade da "Lisnave", eram aquelas que apresentavam os valores médios mais elevados tanto para o TBT ( $1155 \pm 247$ ng $\mathrm{g}^{-1}$ ) como para os correspondentes produtos de degradação, enquanto que ao largo dos "mochões", com águas pouco profundas, as concentrações médias para o TBT eram inferiores a $50 \mathrm{ng} \mathrm{g}^{-1}$.

Estudos recentemente efectuados, vieram confirmar claramente a existência de TBT em amostras de sedimentos situadas a montante do estuário, tendo-se observado concentrações médias compreendidas entre 5 e $35 \mathrm{ng} \mathrm{g}^{-1}$. A figura 4 exemplifica, com recurso á análise por cromatografia de alta resolução seguida de detecção por espectrometria de massa, a existência de TBT numa amostra de sedimento proveniente do estuário do rio Tejo.

Comparativamente aos resultados obtidos para as amostras de água, é necessário entrar em linha de conta que os sedimentos actuam como um repositório do TBT, pelo que as taxas de degradação são substancialmente inferiores às da fase aquosa, levando obviamente à persistência desta forma no meio natural. Apesar dos níveis de TBT até então detectados nos sedimentos do estuário do rio Tejo, serem considerados relativamente elevados e sensíveis às populações biotas aí residentes, não atingiram, no entanto, valores comparáveis aos observados, por exemplo, na baía de Arcachon e no porto de Sidney, de 5000 e 8000 ng $\mathrm{g}^{-1}$, respectivamente.

A presença de outras formas não butiladas, em particular espécies metiladas, foi igualmente alvo de estudos efectuados por Bettencourt e colaboradores. A respectiva detecção em algumas estações de amostragem sugeria a ocorrência de processos biogeoquímicos, levados a cabo pela actividade biológica ao nível dos sedimentos, facto tanto mais evidente quanto maior era a proximidade das descargas de efluentes urbanos. As formas metiladas de estanho sugerem ter origem na actividade biológica exercida sobre o estanho (II) e (IV).

O recente decreto-lei n. ${ }^{\circ 236 / 98}$ de 1 de Agosto, que determina normas, critérios e objectivos de qualidade com a finalidade de proteger o meio aquático nacional, estabelece nos art.os 66 e 67 do capítulo VI, a protecção das águas superficiais e subterrâneas contra a poluição causada pela descarga de substâncias consideradas perigosas. Nesse contexto, a alínea d) do n. ${ }^{\circ} 7$ do art. 67 , prevê para as descargas, o controle da quantidade máxima de cada composto pertencente às listas I e II do Anexo XIX, que incluem todos os grupos de substâncias consideradas proibidas pela actual legislação portuguesa, inclusive os organo-estânicos, com base na toxicidade, 

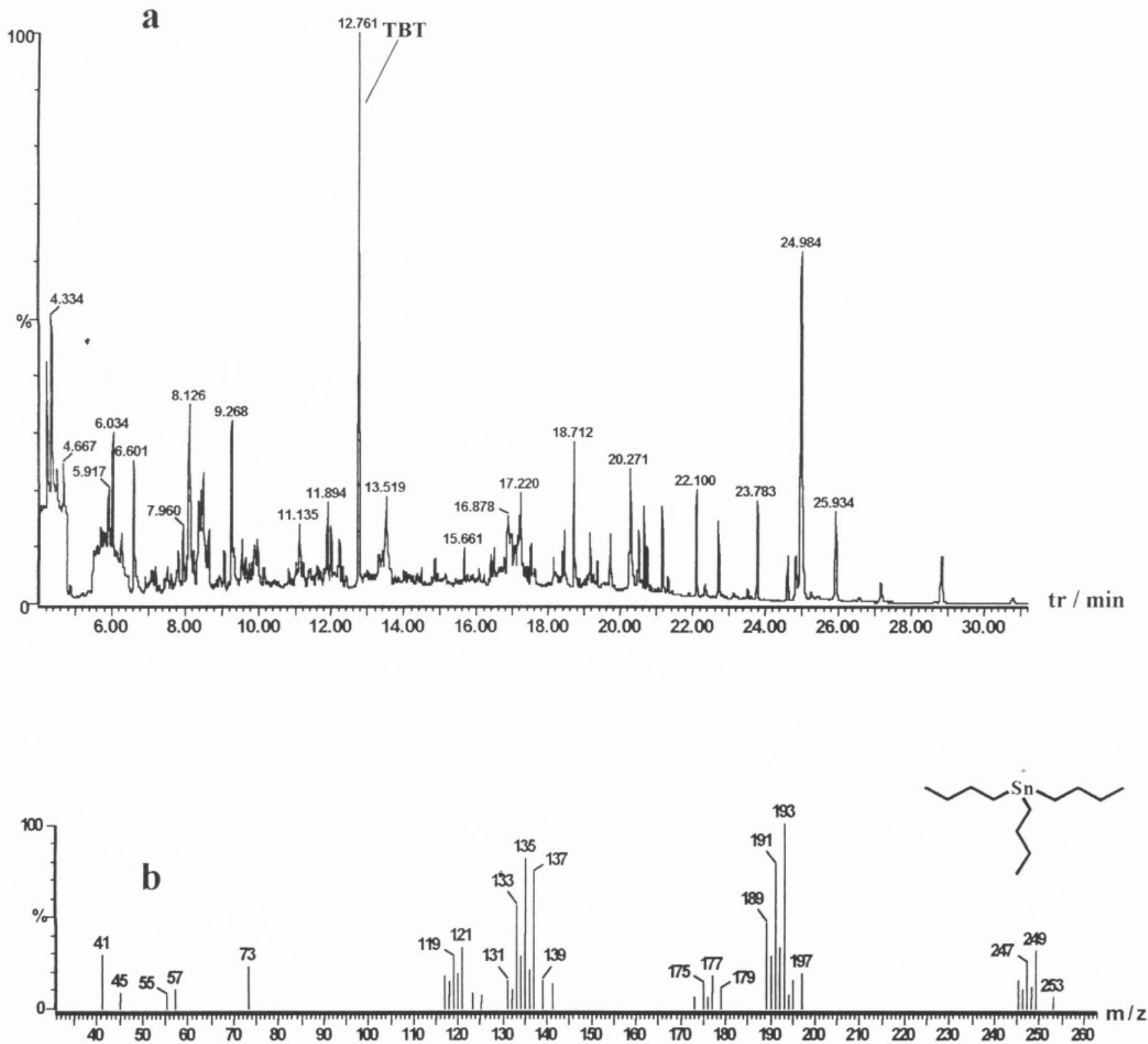

Fig. 4 - Análise de uma amostra de sedimento proveniente do estuário do rio Tejo, com recurso à cromatografia de alta resolução seguida de detecção por espectrometria de massa (CGC/MSD); a) Traçado de corrente iónica total; b) Espectro de massa característico do TBT.

Condições: - Cromatógrafo: Fisons model 8000; Coluna: DB-5 (25m × 0,2mm i.d. $\times 0,33 \mu \mathrm{m}$ de espessura de filme), 95\% dimetilo 5\% difenilo polisiloxano: Programa de temperatura do forno: $50^{\circ} \mathrm{C}$ seguido de incrementos de $10^{\circ} \mathrm{C} / \mathrm{min}$ até $240^{\circ} \mathrm{C}(10 \mathrm{~min})$; Temperatura do injector de vaporização: $320^{\circ} \mathrm{C}$; Velocidade linear do gás de arrastamento (He): $30 \mathrm{~cm} / \mathrm{sec}$; Modo sem repartição de fluxo ("splitless"): 2 min; Injecção ("hot needle"): $1 \mu \mathrm{l}$.

- Espectrómetro de massa: Fisons model Trio 1000; Fonte iónica: $280^{\circ} \mathrm{C}$; Linha de transferência: $300^{\circ} \mathrm{C}$; Energia de ionização: $70 \mathrm{eV}$;

Corrente de ionização $300 \mu \mathrm{A}$; Intervalo de massas: 80 - 1000Da; Pressão: 10-4torr. 
persistência e bio-acumulação. No entanto, não especifica nenhum valor máximo admissível para o TBT, contrariamente a muitas instâncias internacionais, que actualmente o recomendam como inferior a $1 \mathrm{ng} \mathrm{dm}^{-3}$.

Desta forma, os potenciais poluidores ficarão sempre ilibados no que concerne às responsabilidades relativas ao impacte ambiental, causado principalmente pela contaminação sem regra de TBT nos estuários portugueses em geral. Nesta perspectiva, os regulamentos nacionais terão que se adequar e ir mais ao encontro da realidade existente em Portugal, para que uma conjugação de esforços no sentido da salvaguarda dos estuários seja efectivamente uma realidade. Parece difícil aceitar que um bem tão precioso e necessário como a água, esteja a ser negligenciada, justamente pela imprudência do ser vivo mais racional: o Homem.

\section{1- Departamento de Química e Bioquímica da Faculdade de Ciências da Universidade de Lisboa}

2- Departamento de Ecologia da Universidade de Évora

* Sendo $\mathrm{C}_{\mathrm{s}}$ e $\mathrm{C}_{\mathrm{w}}$ respectivamente a concentração nos sedimentos e na fase aquosa.

\section{BIBLIOGRAFIA}

Clarck E.A., Sterritt R. M., Lester J.N., (1988) The Fate of Tributiltin in the Aquatic Environment, Environ. Sci. Technol., 22 (6) 600-604.

Huggett R.J., Unger M.A., Seligman P.F., Valkirs A.O. (1992) The Marine Biocide Tributyltin, Environ. Sci. Technol., 26 (2) 232-237.

Real L.C., (1994) Tintas Marítimas: Protecçāo de Embarcações, Engenho, 41(1) 15-19.

Ritsema R., (1997) Environmental Applications of Hyphenated Techniques for the Speciation of Tin. Arsenic and Mercury: Monitoring butyltin levels in marine environments of the Netherlands, Université de Pau et des Pays de l'Adour; Tese de Doutoramento.

Shebek L., Andrea M.O., Tobschall H. I., (1991) Methyl and Butyltin Compounds in Water and Sediments of Rhine River, Environ. Sci. Technol., 25 (5) 871-878.

Sarradin P.M., Lapaquellerie Y., Astruc A.. Latouche C.. Astruc M., (1995) Long Term Behaviour and Degradation Kinetics of Tributyltin in a Marina Sediment, The Science of Total Environment, 170 59-70.
Kannan K.. Corsolini S. Tanabe S. Tatsukawa R.. (1996) Accumulation Pattern of Butyltin Compounds in Dolphin, Tuna and Shark Collected from Italian Coastal Waters, Environ. Contam. Toxicol., 31 (1) 19-23.

Li Q., Osada M., Takahashi K., Matsutani T., Mori K., (1997) Accumulation and Depuration of Tributyltin Oxide and its Effect on the Fertilisation and Embryonic Development in the Pacific oyster, Crassostrea gigas, Environ. Contam. Toxicol., 58 (3) 489-496.

Kannan K., Falandysz I., (1997) Butyltin Residues in Sediment, Fish, Fish-Eating Birds, Harbour Porpoise and Human Tissues from the Polish Coast of the Baltic Sea, Mar. Pollut. Bull., 34 (3) 203-207.

Alzieu C.L., (1986) TBT Detrimental Effects and Oyster Culture in France - Evolution Since Antifouling Paint Regulation, IEEE Ocean s 86 Conference Proceedings, Washington.

Alzieu C.L., Sanjuan I., Deltreil I.P., Borel M., (1986) Tin Contamination in Arcachon Bay: Effects on oyster shell anomalies, Mar. Pollut. Bull., 17 (11) 494-498.

Lowler I.F., Aldrich I.C., (1987), Sublethal Effects of Bis (Tri-N-Butyltin) Oxide on Crassostrea gigas Spat, Mar. Pollut. Bull., 18 (6) 274-278.

Ellis D.V., Pattisina L.A., (1990) Widespread Neograstropod Imposex: A biological indicator of global TBT contamination?. Mar. Pollut. Bull., 21 (5) 248-253.

Stewart C., De Mora S.J., Jones M.R.L., Miller M.C., (1992) Imposex in New Zealand Neogastropods, Mar. Pollut. Bull. 24 (4) 204-209.
Svavarsson I.. Skarphedinsdottir H... (1995) Imposex in Dogwhelk Nucella lapillus (L.) in Icelandic Waters, Sarcia, 80 (1) $35-40$.

Environmental Oestrogen's: Consequences to Human Health and Wildlife, Assessment A1, MRC, Institute for Environment and Health, University of Leicester, Page Bros., U.K. 1995

Andreae M.O., Byrd I.T., Froelich P.N., (1983) Arsenic, Antimony, Germanium and Tin in the Tejo Estuary, Portugal: Modelling a polluted estuary, Environ. Sci. Technol., 17 (12) 731-737

Bettencourt A.M.M.. Andrae M.O., Cai Y., Gomes M.L. Schebek L., Vilas Boas L.F., Rapsomanikis S., (1997) The Tagus Estuary and Adjoining Coastlines, Special Number of the Netherlands lournal of Aquatic Ecology. Proceeding of the ECSA Local Meeting.

Nogueira J.M.F. Simplicio B. Florêncio M.H. Bettencourt A.M.M. (1998) Analysis of Organotin Compounds in Tagus River by CGC and CGC-MS, Proceedings of $20^{\text {th }}$ International Symposium on $\mathrm{Ca}$ pillary Chromatography, IOPMS, Riva del Garda, Italy.

Nogueira J.M.F., Simplicio B., Florêncio M.H., Bettencourt A.M.M., (1998) Tributyltin Detection in Sediments of Tagus River Estuary by Capillary Gas Chromatography Techniques, submetida para publicação.

Decreto-lei n."236/98 de 1 de Agosto, Diário da República, I SERRIE-A, N." 176 3676-3722.

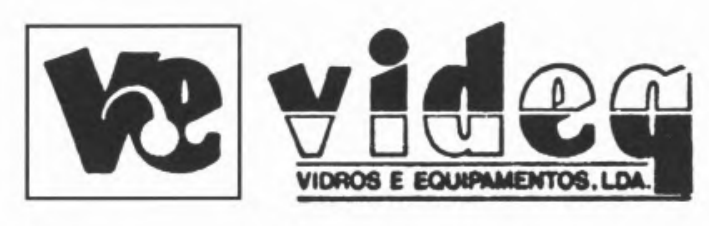

Equipamento de Laboratório

Balanças - Centrifugas - Aparelhos de $\mathrm{pH}$ - Tituladores Condutímetros - Agitadores - Espectrofotómetros Microscópios - etc.

Vidros e Plásticos de Laboratório Distribuidores NORMAX

Material Didáctico

Ensino Secundário e Superior

Representantes exclusivos SISTEDUC - Sistemas Educativos S.A.

Rua Soeiro Pereira Gomes, $15 \mathrm{r} / \mathrm{c}$ Frente Bom Sucesso - 2615 Alverca

Telefs. (01) 95704 20/1/2 - Fax (351-1-957 04 23) - Portugal 